\title{
Schlafapnoe beeinträchtigt oft gar nicht
}

\author{
Eine von fünf Personen im mittleren Alter hat eine mäßige bis schwere obstruktive Schlafapnoe \\ (OSA) - die meisten spüren aber im Alltag nichts davon. Ist der Hype um die OSA übertrieben?
}

_ Für eine Studie zur OSA wurden 522 Personen einer repräsentativen Kohorte der isländischen Bevölkerung eingeladen, die bereits 1990 und 2000 am europäischen Respiratory Health Survey teilgenommen hatten. 415 Personen konnten eingeschlossen werden, 15 wurden bereits wegen einer OSA behandelt. Die Teilnehmer füllten Fragebögen zur Symptomatik und zum Schlafverhalten aus und unterzogen sich einer Polysomnografie sowie einem psychomotorischen Vigilanztest.

Das mediane Alter der Kohorte lag bei 54,7 $\pm 6,8$ Jahren, der BMI bei 28,2 \pm $5,0 \mathrm{~kg} / \mathrm{m}^{2} .16,6 \%$ der Probanden waren aktive Raucher, bei $30,6 \%$ bestand eine bekannte Hypertonie. Jeweils 3\% hatten einen Typ-2-Diabetes, einen Z.n. Schlaganfall bzw. eine KHK.
Anhand des Apnoe-Hypopnoe-Index (AHI) wurde bei $25 \%$ der Teilnehmer eine leichte, bei $13 \%$ eine mäßige und bei 3\% eine schwere OSA festgestellt. 59\% hatten keine OSA. Eine lineare Regressionsanalyse zeigte einen Einfluss von Geschlecht, Alter und BMI, nicht aber von Raucherstatus und Hypertonie.

Die Schwere der OSA korrelierte auch nicht mit metabolischen und kardiovaskulären Erkrankungen oder - besonders überraschend - mit Symptomen des Schlafmangels wie Tagesmüdigkeit oder Konzentrationsstörungen.

Bei den objektiven Tests von Vigilanz, Reaktionszeit und Fehlerhäufigkeit bestand zwar ein signifikanter Unterschied, allerdings wurde dieser ausschließlich durch die kleine Gruppe mit AHI $\geq 30(n=12)$ verursacht.
- Arnardottir ES, Bjornsdottir E, Olafsdottir KA et al. Obstructive sleep apnoea in the general population: highly prevalent but minimal symptoms. Eur Respir J. 2016:47:194-202

\section{KOMMENTAR}

Nach dieser Studie hat zwar fast jeder Fünfte im mittleren Lebensalter eine OSA - für die Entwicklung von Tagesmüdigkeit, Konzentrationsstörungen, $\mathrm{Hy}$ pertonie oder KHK spielt das aber außer in der kleinen Gruppe mit sehr hohem AHI kaum eine Rolle. Defizite der Vigilanz waren bei leichter bis mäßiger OSA nicht einmal in Testsituationen nachweisbar. Die bloße Feststellung einer OSA in der Polysomnografie sollte also nicht automatisch zu einer - oft wenig akzeptierten - therapeutischen Maßnahme führen, da sich das Befinden der Patienten kaum bessern dürfte.

Prof. Dr. med. H. S. FüeßI

\section{Balanitis circinata}

Ein 37-jähriger Mann stellte sich mit Hautläsionen am Penis vor. Er gab an, dass er etwa $4 \mathrm{~kg}$ an Gewicht verloren hatte, sich müde und leistungsschwach fühlte und Rückenschmerzen hatte. Gastrointestinale Symptome lagen nicht vor. Zwei Monaten zuvor hatte er eine Episode von Dysurie und Ausfluss aus der Harnröhre gehabt, doch beides hatte sich spontan zurückgebildet. Der Mann stand nicht unter einer Dauermedikation, die medizinische Vorgeschichte war unauffällig.

Bei der Untersuchung erkannte man gerötete, scharf markierte, ringförmige Plaques an der Glans penis und eine entzündliche Reaktion am Orificium externum (Abb. A, B). Zudem wiesen beide Augen eine konjunktivale Injektion auf. Der HIV-Test war positiv. Die Viruslast betrug 15.000 Kopien/ml, die CD4-Zellzahl 172/ $\mu$ l. Der Test auf Rheumafaktor fiel negativ aus, der HLA-B27-Test hingegen positiv. Serologische Untersuchungen auf Hepatitis B und C sowie Syphilis waren negativ. Die PCR in einem Urethralabstrich ergab Chlamydia trachomatis.

Der Mann wurde mit einer Einzeldosis von $1 \mathrm{~g}$ Azithromycin behandelt, zusätzlich begann man eine antiretrovirale Therapie. Weil die Veränderungen am Penis vier Wochen später immer noch be-
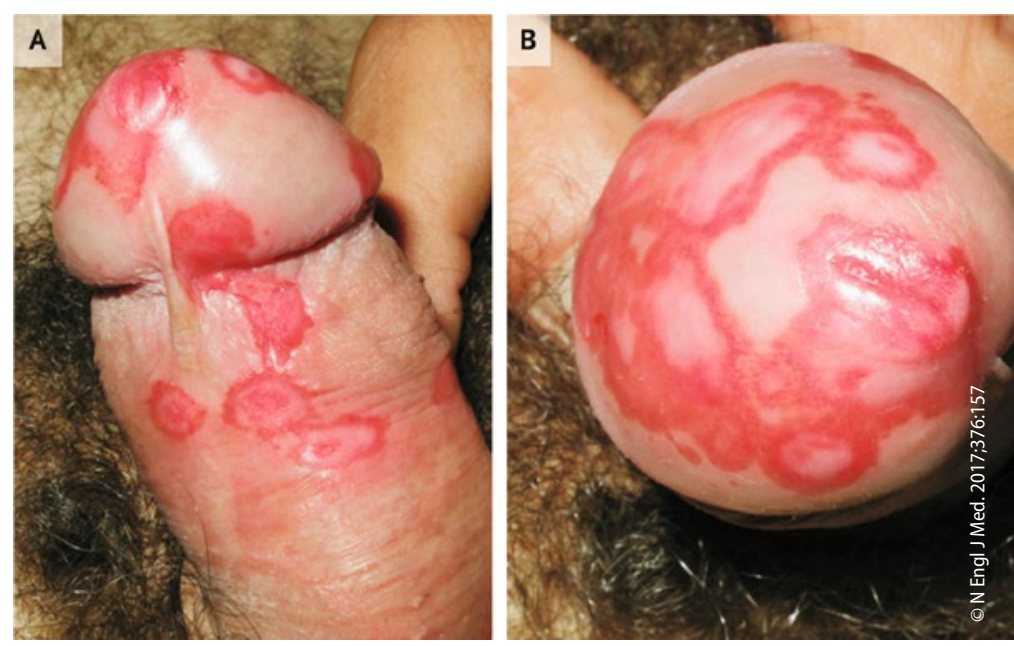

A, B: Scharf markierte, ringförmige Plaques an der Glans penis, Entzündung am Orificium externum.

standen, behandelte man mit 0,1\%-Tacrolimus-Creme. Innerhalb von zehn Tagen kam es zur vollständigen Rückbildung.

Prof. Dr. med. H. S. FüeßI

- Pulido-Perez A, Suarez-FernandezR (ana.pulido@salud.madrid.org):Circinate balanitis.NEngl JMed. 2017;376:157 